\title{
Prognostic Features of BCR-ABL Genetic Variations in Acute Lymphoblastic Leukemia
}

\author{
Dina Adel Fouad1, Hasnaa A. Abo_Elwafa², Shereen Philip Aziz'², Ahmed A. Allam², \\ Nesma Mokhtar ${ }^{2}$ \\ ${ }^{1}$ Clinical Pathology Department, Faculty of Medicine, Ain Shams University, Cairo, Egypt \\ ${ }^{2}$ Clinical Pathology Department, Faculty of Medicine, Sohag University, Sohag, Egypt \\ Email: *sanymn@yahoo.com
}

How to cite this paper: Fouad, D.A., Abo_Elwafa, H.A., Aziz, S.P., Allam, A.A. and Mokhtar, N. (2018) Prognostic Features of BCR-ABL Genetic Variations in Acute Lymphoblastic Leukemia. Open Journal of Blood Diseases, 8, 90-100. https://doi.org/10.4236/ojbd.2018.84010

Received: November 27, 2018

Accepted: December 24, 2018

Published: December 27, 2018

Copyright $\odot 2018$ by authors and Scientific Research Publishing Inc. This work is licensed under the Creative Commons Attribution International License (CC BY 4.0).

http://creativecommons.org/licenses/by/4.0/

\begin{abstract}
Background: Acute lymphoblastic leukemia (ALL) is a hematologic malignancy which results from accumulation of lymphoid progenitor cells in the bone marrow and/or extramedullary sites. Philadelphia chromosome $\left(\mathrm{Ph}^{1}\right)$ positive ALL, a high-risk cytogenetic subset, accounts for $25 \%-30 \%$ of adult ALL cases but occurs in less than $5 \%$ of children. We aimed with this study to detect BCR-ABL genes fusion, amplification and deletion in ALL patients, using extrasignal-fluorescence in situ hybridization (ES-FISH), and to assess their relation with other standard prognostic factors and therapeutic response. Patients and Methods: This study was carried out on 39 newly diagnosed ALL patients. All patients were subjected to: history, clinical examination and laboratory investigations, which included complete blood count $(\mathrm{CBC})$, peripheral blood $(\mathrm{PB})$, bone marrow $(\mathrm{BM})$ examination, immunophenotyping and fluorescence in situ hybridization using extra-signal probe to detect BCR-ABL genes fusion. Results: This study showed statistical analysis of patients' $t(9 ; 22)$ with other factors revealed, significant association $(\mathrm{p}<0.05)$ of $\mathrm{t}(9 ; 22)$ with patients outcome, age $>35$ years, hepatosplenomegaly, absence of lymphadenopathy, TLC $\geq 50 \times$ $10^{9} / \mathrm{L}$, absolute $\mathrm{PB}$ blasts $\geq 4.4 \times 10^{9} / \mathrm{L}$, immunophenotyping and other aberrations. Conclusion: BCR/ABL fusion gene analysis by ES-FISH may serve as a prognostic marker in adulthood ALL. The age, TLC and $t(9 ; 22)$ represent the significant standard prognostic factors in relation to patients' outcome.
\end{abstract}

\section{Keywords}

Acute Lymphoblastic Leukemia, Philadelphia Chromosome-Positive, Extrasignal-Fluorescence In Situ Hybridization 


\section{Introduction}

Acute lymphoblastic leukemia (ALL) is a hematological malignancy propagated by impaired differentiation, proliferation, and accumulation of lymphoid progenitor cells in the bone marrow and/or extramedullary sites [1]. Cytogenetic abnormalities are independent prognostic variables for predicting the outcome of ALL. Recent genomic studies have analyzed various cytogenetic abnormalities of ALL and increased the number of potential prognostic markers [2].

Adult and childhood ALL differ markedly in the prevalence of various cytogenetic abnormalities. Philadelphia chromosome $\left(\mathrm{Ph}^{1}\right)$ positive $\mathrm{ALL}$, a high-risk cytogenetic subset, accounts for $25 \%$ - $30 \%$ of adult ALL cases but occurs in less than $5 \%$ of children [3].

$\mathrm{Ph}$ chromosome $\left(\mathrm{ph}^{1}\right)$ results from a reciprocal translocation that fuses the Abelson tyrosine kinase (ABL1) from chromosome 9 to the breakpoint cluster region (BCR) on chromosome 22 [4].

Fluorescence in Situ Hybridization (FISH) technology represents an important advancement in cytogenetics. FISH is a marriage of classical cytogenetics and molecular technologies that has a large number of applications [5]. FISH uses fluorescent DNA probes to target specific chromosomal locations within the nucleus, resulting in colored signals that can be detected using a fluorescent microscope [6].

The first generation of BCR/ABL single fusion FISH probes detected the fusion gene with high specificity (false positive rate 5\%) but with a low sensitivity. A new generation of FISH probes has been developed with the rationale to define the $t(9 ; 22)$ by two FISH events: a fusion signal and an extra signal (ES) corresponding either to the remaining probe on the $9 \mathrm{q}+$ or to a second fusion on the $9 \mathrm{q}+$, according to the breakpoint localization in the BCR gene. With these new ES probe, the cut off rate for false positives has dropped significantly to $3 \%$. [7].

Extra-signal FISH is a fast and cost effective technique not only to evaluate BCR/ABL fusion in ALL and CML but moreover able to discriminate various rearrangement of $\mathrm{BCR} / \mathrm{ABL}$ into major \& minor fusions, $\mathrm{ABL} \& \mathrm{BCR}$ deletion, duplication and amplification [8].

\section{Aim of the Work}

This work aims to detect BCR-ABL genes fusion in acute lymphoblastic leukemia patients, using extra-signal fluorescence in situ hybridization (ES-FISH), and to assess their relation with other standard prognostic factors and therapeutic response.

\section{Patients and Methods}

\subsection{Patients}

This study was carried out on 39 newly diagnosed ALL patients who were attending the hematology oncology clinics of Ain Shams University Hospitals. 
This study had been approved by Research and Ethical committee at faculty of medicine of Sohag University and informed consent was obtained from patients to use their samples in this study.

All patients were subjected to the following:

1) History and clinical examination.

2) Laboratory investigations, which included:

CBC using Sysmex XN-1000 with examination of leishman stained PB smears laying stress on differential leucocytic count, assessment of blast cell number and morphology. BM aspiration and examination of leishman stained smears was performed. Immunophenotyping on BM or PB samples, performed on EPICS XL Coulter Flow cytometer (FCM), USA. Fluorescence in situ hybridization using the following probes:

- LSI dual color single fusion and double fusion BCR/ABL probes for detection of $\mathrm{t}(9 ; 22)$ (q34; q11).

- LSI dual color extrasignal BCR/ABL probe for detection of $t(9 ; 22)$ with other aberrations as; amplification, deletion or duplication.

- LSI dual color double fusion TCF2/PBX1 for detection of $t(1 ; 19)$ (q23; p13.3).

- LSI dual color break apart rearrangement MLL probe for detection of 11q23 rearrangement.

\subsection{Methods}

For each case, $500 \mu \mathrm{L}$ of $\mathrm{PB} / \mathrm{BM}$ sample added to $5 \mathrm{~mL}$ of sterile culture tube for the step of harvesting and then slide preparation; 2 or 3 drops of cell suspension were added by a Pasteur pipette to the slides, using a light microscope and the area of maximum metaphase concentration was marked on each slide. The probe mixture ( $2 \mu$ distilled water, $1 \mu$ probe and $7 \mu$ hybridization buffer) was applied on each slide at the marked area and immediately covered with a glass cover slip. The slides were denatured at $80^{\circ} \mathrm{C}$ in hybrite for 5 minutes, then, incubated overnight at $37^{\circ} \mathrm{C}$ in a dark pre-warmed humidified chamber, to allow probe hybridization. Post hybridization wash is the last step and so the slides are ready to be examined under the fluorescent microscope.

\subsection{Interpretation and Signals' Patterns}

- Dual color single fusion LSI BCR-ABL probe: Negative (normal pattern): 2 red signals (2R) and 2 green signals (2G). Positive: 1 yellow signal (1Y), 1 red $(1 \mathrm{R})$ and 1 green $(1 \mathrm{G})$ signals. Cut off: $10 \%$.

- Dual color dual fusion LSI BCR-ABL probe: Negative (normal pattern): 2 red signals and 2 green signals. Positive: 2 yellow, 1 red and 1 green signals. Cut off: $1.3 \%$.

- LSI BCR/ABL ES dual Color translocation probe: Negative (normal pattern): 2 red signals and 2 green signals. MBCR: 1 yellow, 2 red and 1 green signals. mBCR: 2 yellow, 1 red and 1 green signals. ABL deletion: 1 yellow, 1 red and 1 green signals. Cut off: $10 \%$.

- Dual color dual fusion LSI TCF2-PBX1probe: Negative (normal pattern): 2 
red signals and 2 green signals. Positive: 2 yellow, 1 red and 1 green signals. Cut off: $1.3 \%$.

- Dual color LSI break apart MLL probe: Negative (normal pattern): 2 yellow signals. Positive: 1 yellow, 1 red and 1 green signals. Cut off: $1.3 \%$.

\subsection{Statistical Analysis Methods}

IBM SPSS statistics (V. 22.0, IBM Corp., USA, 2013) was used for data analysis. Data were expressed as both number and percentage for categorized data. Chi-square test used to study the association between 2 variables or comparison between 2 independent groups as regards the categorized data. The probability of error at 0.05 was considered significant, while at 0.01 and 0.001 are highly significant.

\section{Results}

Clinical findings: Out of ALL patients; 24 (61.5\%) were males and 15 (38.5\%) were females with male to female ratio of (1.6:1). Age range was from 19 year to 71 years old.19 (48.7\%) patients presented with hepatomegaly, 20 (51.3\%) patients presented with splenomegaly, 24 (61.5\%) patients presented with lymphadenopathy and 2 (5.1\%) patients presented with CNS infiltration.

Laboratory findings: In the current study the hemoglobin level $(\mathrm{Hb})$ ranged from 4.6 to $10.1 \mathrm{~g} / \mathrm{dl}$ with a mean value of $(7.35 \pm 1.6) \mathrm{g} / \mathrm{dl}$. Total leucocytic count (TLC) ranged from 2.6 to $101 \times 10^{9} / \mathrm{L}$ with a mean value of $(51.8 \pm 30.2) \times$ $10^{9} / \mathrm{L}$. The platelets count ranged from 33 to $128 \times 10^{9} / \mathrm{L}$ with a mean value of $(80.5 \pm 26.7) \times 10^{9} / \mathrm{L}$. Absolute peripheral blood blast ranged from 2 to $61 \times$ $10^{9} / \mathrm{L}$ with a mean value of $(31.5) \times 10^{9} / \mathrm{L}$. Bone Marrow Examination: According to WHO classification, The absolute BM blast ranged from 24 to $98 \times 10^{9} / \mathrm{L}$ with a mean value $(66 \pm 21) \times 10^{9} / \mathrm{L}$. Immunophenotyping (IPT): 26 patients were expressing CD10. Among them CD13 and CD33 were positive in 6 patients.

\section{Fluorescence in Situ Hybridization Analysis:}

Metaphase and/or interphase FISH analysis were successfully performed on 39 $\mathrm{BM}$ and/or $\mathrm{PB}$ samples and revealed the following:

Structural aberrations, Positive results for $t(9 ; 22)$ was encountered in 11 (28.2\%) patients, 11 (q23) was detected in $2(5.1 \%)$ patients, $t(1 ; 19)$ was detected in $1(2.5 \%)$ patient and $\mathrm{ph}^{1}$ with other aberrations were present in 8 cases of 11 patients in the form of the following: ABL amplifications were observed in 3 cases with a frequency of $7.6 \%$, derivative chromosome $9 \mathrm{q} 34$ deletion were observed in 3 cases with a frequency of 7.6\%, duplication was observed in 1 case with a frequency of $2.56 \%$ and $1 \%$ case showed combination of amplification and deletion with a frequency of $2.65 \%$ in ALL patients (Figure $1 \&$ Figure 2) and (Photo $1 \&$ Photo 2).

\section{Follow up \& clinical outcome of studied all patients:}

Follow up was done at day 14 of chemotherapy. Out of the 39 newly diagnosed patients, 16 (41\%) patients achieved complete remission; while 23 (59\%) patients showed incomplete remission. 


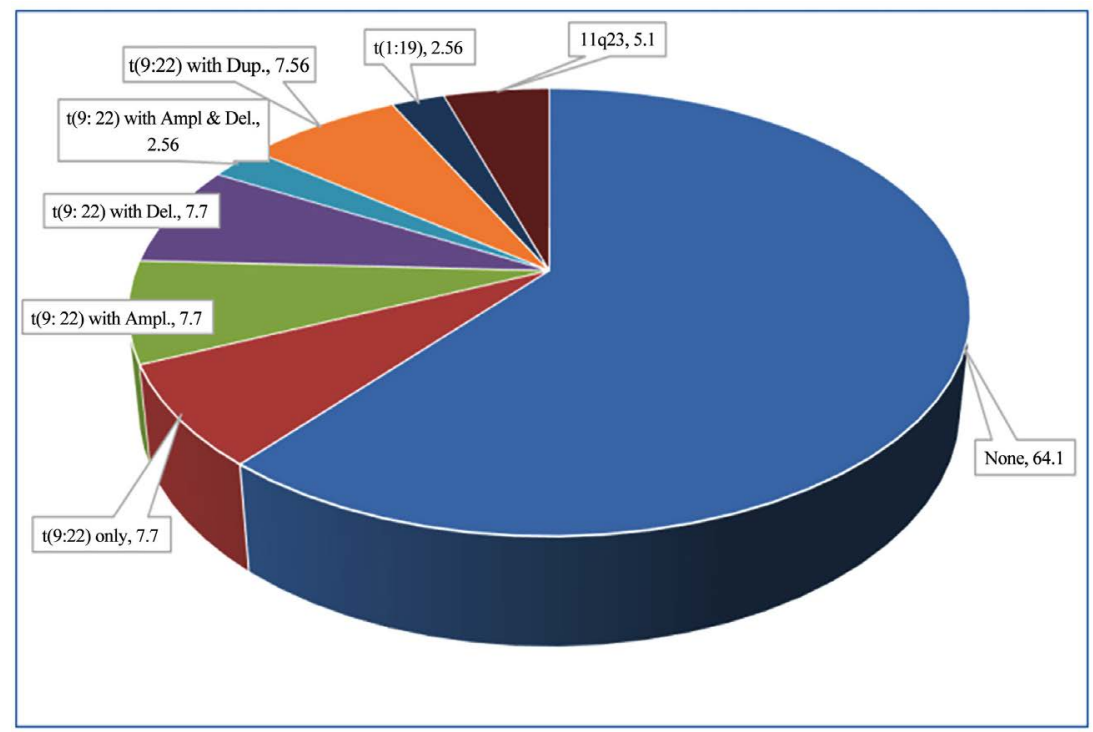

Figure 1. A pie chart results of structural aberrations in all patients. Structural aberrations are detected in $14 / 39(35.9 \%)$, among them $t(9 ; 22)$ is the most common (78.5\%).

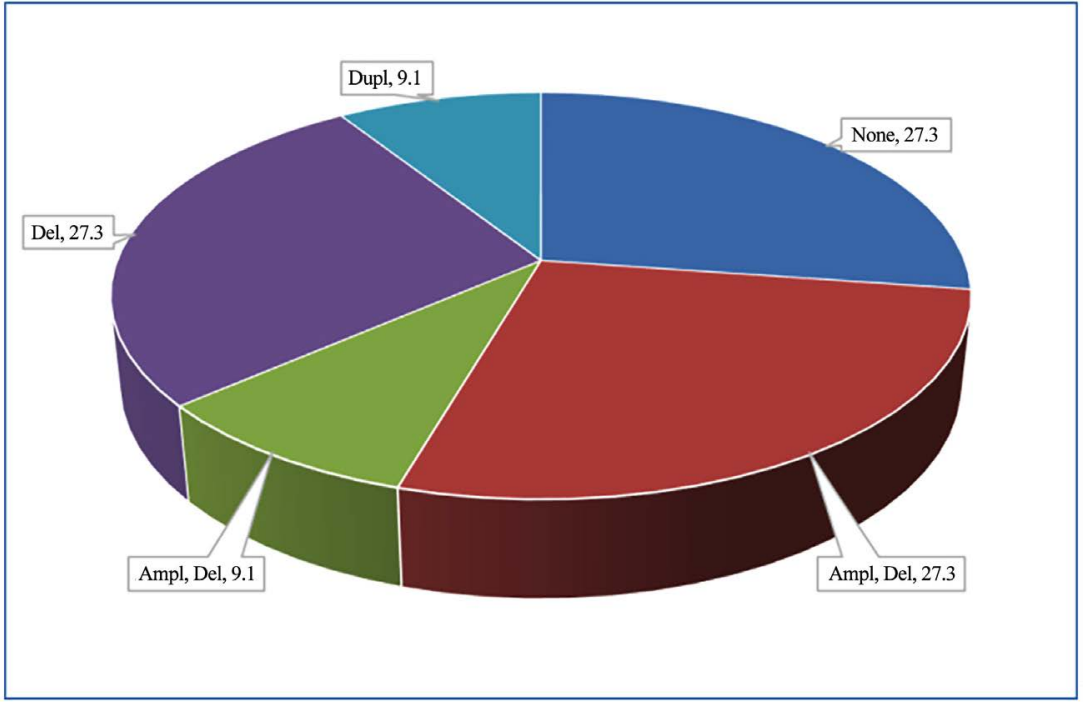

Figure 2. A pie chart results of aberrations types in patients with $t(9 ; 22)$.

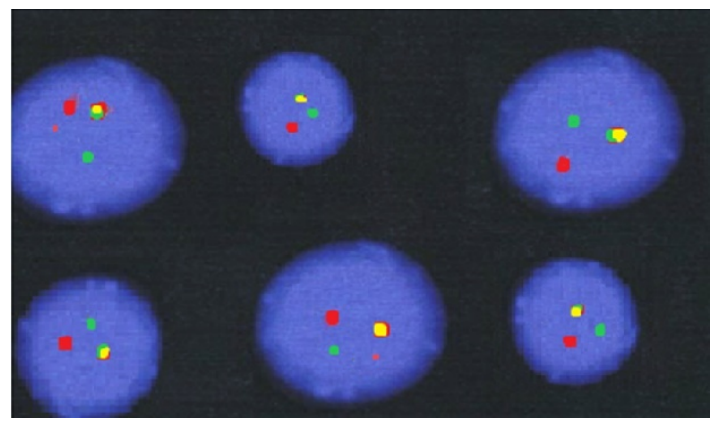

Photo 1. Deletion of ABL gene by ES-FISH in interphase cells withsignal pattern of 1 Y 1 G1R in $59 \%$ of cells. 


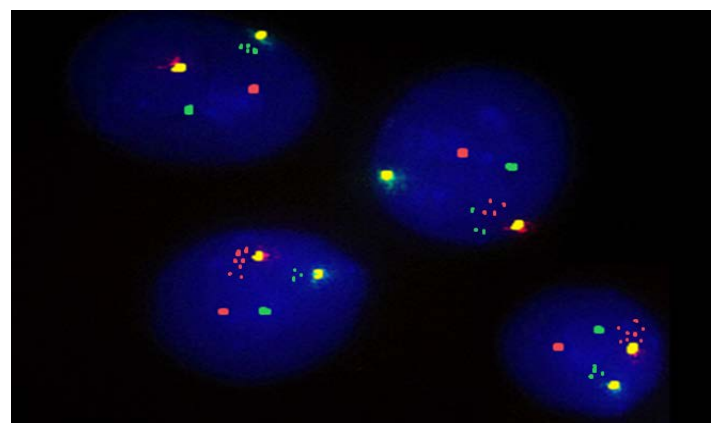

Photo 2. mBCR/ABL1 by ES-FISH in interphase cells showed a signal pattern of 2Y1G1R associated with amplification of both ABL gene (mutiple copies of ABL gene in red) and BCR gene (mutiple copies of BCRgene in green) in $22 \%$ of cells.

\section{Results of ALL patients' $t(9 ; 22)$ in relation to different prognostic factors:}

Showed significant association $(\mathrm{p}<0.05)$ of $\mathrm{ph}^{1}+$ ve patients with age $>35$ years, hepatosplenomegaly, absence of lymphadenopathy, TLC $\geq 50 \times 10^{9} / \mathrm{L}$ and absolute PB blasts $\geq 4.4 \times 10^{9} / \mathrm{L}$, immunophenotyping and other aberrations. On the other hand, gender, CNS infilteration, $\mathrm{Hb}$ and platelet count showed non-significant statistical difference $(\mathrm{p}>0.05)$ (Table 1).

Results of patients' $t(9 ; 22)$ with other aberrations in relation to different prognostic factors:

Showed a significant positive association between other aberrations and age $\geq$ 35 years and also with absolute PB blasts $\geq 4.4 \times 10^{9} / \mathrm{L}$ with $(\mathrm{p}<0.05)$. With no significance to other prognostic factors $(\mathrm{p}>0.05)$ (Table 2$)$.

\section{Discussion}

In the present work BCR/ABL fusion was detected in 11 patients (28.2\%). This is in concordance with Ghazavi F et al. [3] who reported that BCR/ABL fusion gene is presented with an incidence about $30 \%$ in adult but slightly higher than Noreen et al. [9] who reported that BCR/ABL fusion gene is detected with an incidence $20.3 \%$.

Moreover MLL (11q23) gene rearrangements were presented in 2 patients (5.1\%) which lesser than Schafer et al. [10] who reported MLL gene rearrangement with $10 \%$ in adult ALL and $8 \%$ of pediatric ALL with about $80 \%$ of them in infants. The $t(1 ; 19)$ was encountered in one patient $(2.56 \%)$ which is in concordance with Al Ustwania et al. [11] who reported $t(1 ; 19) 3 \%$ in adult ALL.

Using ES-FISH probe, interphase analysis showed $28.2 \%$ positivity for the $B C R-A B L$ fusion gene in the form of; minor pattern in 4 cases (36.4\%), major pattern in 1 case $(9.1 \%)$ and mixed pattern in 6 cases (54.5\%) which differs from Ilana de Franc et al. [12] who observed a $32.2 \%$ positivity for the $B C R-A B L$ fusion gene in $31 \mathrm{~B}$-cell adult ALL patients including the minor (40\%), major (30\%) and both forms (30\%) and differ from Steven et al. [13] who observed half of ALL patients with $B C R-A B L$ fusion gene had major pattern and another half had minor pattern. 
Table 1. ALL patients' $t(9 ; 22)$ in relation to different prognostic factors.

\begin{tabular}{|c|c|c|c|c|c|c|c|c|c|}
\hline \multirow{3}{*}{ Parameter } & \multirow{3}{*}{ Groups } & \multirow{3}{*}{ No. } & \multirow{3}{*}{$\%$} & \multicolumn{4}{|c|}{$t(9 ; 22)($ total No. $=11)$} & \multirow{3}{*}{$\mathbf{P}$} & \multirow{3}{*}{ Significance } \\
\hline & & & & \multicolumn{2}{|c|}{$+\mathrm{ve}$} & \multicolumn{2}{|c|}{$-v e$} & & \\
\hline & & & & No. & $\%$ & No. & $\%$ & & \\
\hline \multirow{2}{*}{ Age (Years) } & $\geq 35$ & 18 & 46.2 & 9 & 81.8 & 9 & 32.1 & \multirow{2}{*}{0.005} & \multirow{2}{*}{ HS } \\
\hline & $<35$ & 21 & 53.8 & 2 & 18.2 & 19 & 67.9 & & \\
\hline \multirow{2}{*}{$\begin{array}{l}\text { Gender } \\
\text { M/F: } 1.6: 1\end{array}$} & Male & 24 & 61.5 & 7 & 63.6 & 17 & 60.7 & \multirow{2}{*}{0.866} & \multirow{2}{*}{ NS } \\
\hline & Female & 15 & 38.5 & 4 & 36.4 & 11 & 39.3 & & \\
\hline \multirow{2}{*}{ Hepatomegaly } & Yes & 19 & 48.7 & 11 & 100 & 8 & 28.6 & \multirow{2}{*}{0.000} & \multirow{2}{*}{ HS } \\
\hline & No & 20 & 51.3 & 0 & 0 & 20 & 71.4 & & \\
\hline \multirow{2}{*}{ Splenomegaly } & Yes & 20 & 51.3 & 11 & 100 & 9 & 32.1 & \multirow{2}{*}{0.000} & \multirow{2}{*}{ HS } \\
\hline & No & 19 & 48.7 & 0 & 0 & 19 & 67.9 & & \\
\hline \multirow{2}{*}{ Lymphadenopathy } & Yes & 24 & 61.5 & 1 & 9.1 & 23 & 82.1 & \multirow{2}{*}{0.000} & \multirow{2}{*}{ HS } \\
\hline & No & 15 & 38.5 & 10 & 90.9 & 5 & 17.9 & & \\
\hline \multirow{2}{*}{ CNS Infilteration } & Yes & 2 & 5.1 & 1 & 9.1 & 1 & 3.6 & \multirow{2}{*}{0.482} & NS \\
\hline & No & 37 & 94.9 & 10 & 90.9 & 27 & 96.4 & & \\
\hline Wh & $<10 \mathrm{~g} / \mathrm{dl}$ & 36 & 92.3 & 9 & 81.8 & 27 & 96.4 & 0123 & NS \\
\hline HD & $\geq 10 \mathrm{~g} / \mathrm{dl}$ & 3 & 7.7 & 2 & 18.2 & 1 & 3.6 & 0.123 & NS \\
\hline $\operatorname{TI} C\left(\times 10^{9} / \mathrm{I}\right)$ & $<50$ & 26 & 66.7 & 3 & 27.3 & 23 & 82.1 & 0001 & HS \\
\hline & $\geq 50$ & 13 & 33.3 & 8 & 72.7 & 5 & 17.9 & 0.001 & HS \\
\hline Platelet count $\left(\times 10^{9} / \mathrm{L}\right)$ & $<100$ & 33 & 84.6 & 11 & 100 & 22 & 78.6 & 0095 & NS \\
\hline Platelet count $(\times 107 \mathrm{~L})$ & $\geq 100$ & 6 & 15.4 & 0 & 0 & 6 & 21.4 & 0.095 & NS \\
\hline Ahsolute PB Rlasts & $<4.4$ & 19 & 48.7 & 1 & 9.1 & 18 & 64.3 & 0002 & $\mathrm{HS}$ \\
\hline Absolute PB Blasts & $\geq 4.4$ & 20 & 51.3 & 10 & 90.9 & 10 & 35.7 & 0.002 & HS \\
\hline & CD10: & & & & & & & & \\
\hline & Positive & 26 & 66.7 & 6 & 54.5 & 20 & 71.4 & 0214 & NS \\
\hline IDT & Negative & 13 & 33.3 & 5 & 45.5 & 8 & 28.6 & 0.314 & NS \\
\hline $1 P 1$ & CD13/33: & & & & & & & & \\
\hline & Positive & 5 & 12.8 & 5 & 45.5 & 0 & 0 & 0000 & $\mathrm{HS}$ \\
\hline & Negative & 34 & 87.2 & 6 & 54.5 & 28 & 100 & 0.000 & $\mathrm{HS}$ \\
\hline Other Aherrations & Yes & 11 & 28.2 & 11 & 100 & 0 & 0 & 0000 & HS \\
\hline Other Aberrations & No & 28 & 71.8 & 0 & 0 & 28 & 100 & 0.000 & $\mathrm{HS}$ \\
\hline & None & 31 & 79.5 & 3 & 27.3 & 28 & 100 & & \\
\hline & Ampl & 3 & 7.7 & 3 & 27.3 & 0 & 0 & & \\
\hline Aberrations Type & Ampl, Del & 1 & 2.6 & 1 & 9.1 & 0 & 0 & 0.000 & HS \\
\hline & Del & 3 & 7.7 & 3 & 27.3 & 0 & 0 & & \\
\hline & Dupl & 1 & 2.6 & 1 & 9.1 & 0 & 0 & & \\
\hline
\end{tabular}

P: Prevelance HS: Highly Significant, S: Significant, NS: None Significant, Hb: hemoglobin, TLC: total leucocytic count, IPT; Immunophenotyping, Ampl: Amplification, Del: Deletion, Dupl: Duplication.

Table 2. ALL patients' $t(9 ; 22)$ with other aberrationsin relation to different prognostic factors.

\begin{tabular}{|c|c|c|c|c|c|c|c|c|c|c|c|c|c|}
\hline \multirow{3}{*}{ Parameter } & \multirow{3}{*}{ Groups } & \multirow{3}{*}{ NO. } & \multirow{3}{*}{$\%$} & \multicolumn{8}{|c|}{ ACAs } & \multirow{3}{*}{$\mathbf{P}$} & \multirow{3}{*}{ Significance } \\
\hline & & & & \multicolumn{2}{|c|}{ Ampl } & \multicolumn{2}{|c|}{ Ampl, Del } & \multicolumn{2}{|c|}{ Del } & \multicolumn{2}{|c|}{ Dupl } & & \\
\hline & & & & No. & $\%$ & No. & $\%$ & No. & $\%$ & No. & $\%$ & & \\
\hline \multirow{2}{*}{ Age (Years) } & $\geq 35$ & 7 & 87.5 & 3 & 100 & 1 & 100 & 3 & 100 & 0 & 0 & \multirow{2}{*}{0.046} & \multirow{2}{*}{ S } \\
\hline & $<35$ & 1 & 12.5 & 0 & 0 & 0 & 0 & 0 & 0 & 1 & 100 & & \\
\hline
\end{tabular}


Continued

\begin{tabular}{|c|c|c|c|c|c|c|c|c|c|c|c|c|c|}
\hline Gender & Male & 5 & 62.5 & 2 & 66.7 & 1 & 100 & 2 & 66.7 & 0 & 0 & \multirow{2}{*}{0.510} & \multirow{2}{*}{ NS } \\
\hline M/F: $1.6: 1$ & Female & 3 & 37.5 & 1 & 33.3 & 0 & 0 & 1 & 33.3 & 1 & 100 & & \\
\hline Hepatomegaly & Yes & 8 & 100 & 3 & 100 & 1 & 100 & 3 & 100 & 1 & 100 & * & * \\
\hline Splenomegaly & Yes & 8 & 100 & 3 & 100 & 1 & 100 & 3 & 100 & 1 & 100 & * & * \\
\hline \multirow{2}{*}{ Lymphadenopathy } & Yes & 1 & 12.5 & 0 & 0 & 0 & 0 & 1 & 33.3 & 0 & 0 & \multirow{2}{*}{0.592} & \multirow{2}{*}{ NS } \\
\hline & No & 7 & 87.5 & 3 & 100 & 1 & 100 & 2 & 66.7 & 1 & 100 & & \\
\hline CNS Infilteration & NO & 8 & 100 & 3 & 100 & 1 & 100 & 3 & 100 & 1 & 100 & * & * \\
\hline \multirow{2}{*}{$\mathrm{Hb}$} & $<10 \mathrm{~g} / \mathrm{dl}$ & 6 & 75 & 2 & 66.7 & 0 & 0 & 3 & 100 & 1 & 100 & \multirow{2}{*}{0.217} & \multirow{2}{*}{ NS } \\
\hline & $\geq 10 \mathrm{~g} / \mathrm{dl}$ & 2 & 25 & 1 & 33.3 & 1 & 100 & 0 & 0 & 0 & 0 & & \\
\hline \multirow{2}{*}{ TLC $(\times 109 / \mathrm{L})$} & $<50$ & 2 & 25 & 0 & 0 & 0 & 0 & 1 & 33.3 & 1 & 100 & \multirow{2}{*}{0.217} & \multirow{2}{*}{ NS } \\
\hline & $\geq 50$ & 6 & 75 & 3 & 100 & 1 & 100 & 2 & 66.7 & 0 & 0 & & \\
\hline Platelet count $(\times 109 / \mathrm{L})$ & $<100$ & 8 & 100 & 3 & 100 & 1 & 100 & 3 & 100 & 1 & 100 & * & * \\
\hline \multirow{2}{*}{ Absolute PB Blasts } & $<4.4$ & 1 & 12.5 & 0 & 0 & 0 & 0 & 0 & 0 & 1 & 100 & \multirow{2}{*}{0.046} & \multirow{2}{*}{ S } \\
\hline & $\geq 4.4$ & 7 & 87.5 & 3 & 100 & 1 & 100 & 3 & 100 & 0 & 0 & & \\
\hline \multirow{6}{*}{ IPT } & CD10: & & & & & & & & & & & \multirow{4}{*}{0.446} & \multirow{4}{*}{ NS } \\
\hline & Positive & 4 & 50 & 1 & 33.3 & 0 & 0 & 2 & 66.7 & 1 & 100 & & \\
\hline & Negative & 4 & 50 & 2 & 66.7 & 1 & 100 & 1 & 33.3 & 0 & 0 & & \\
\hline & CD13/33: & & & & & & & & & & & & \\
\hline & Positive & 4 & 50 & 2 & 66.7 & 1 & 100 & 1 & 33.3 & 0 & 0 & \multirow{2}{*}{0.446} & \multirow{2}{*}{ NS } \\
\hline & Negative & 4 & 50 & 1 & 33.3 & 0 & 0 & 2 & 66.7 & 1 & 100 & & \\
\hline
\end{tabular}

P: Prevelance HS: Highly Significant, S: Significant, NS: None Significant, Hb: hemoglobin, TLC: total leucocytic count, IPT; Immunophenotyping, ACAs: Additional chromosomal abnormalities, Ampl: Amplification, Del: Deletion, Dupl: Duplication. ${ }^{\star}$ No statistical comparison could be done as all cases had hepatosplenomegaly, Plts $<100 \times 109 / \mathrm{L}$ and no CNS infilteration.

Other aberrations associated with $\mathrm{ph}^{1}$ positive patients were presented in 8 cases (72.7\%). This is in concordance with Chang Ahn et al. [14] who reported the presence of other aberrations associated with $\mathrm{ph}^{1}$ with an incidence (73\%). On the other hand, out of the total 39 patients in our study other aberrations associated with $\mathrm{ph}^{1}$ represented (20.5\%). Derivative chromosome 9q34 deletion was observed in 3 patients (7.7\%) and the fourth showed deletion associated with amplification (2.56\%). Duplication was observed in 1 patient $(2.56 \%)$ while $\mathrm{ABL}$ amplifications were observed in 3 patients (7.7\%) and the fourth was presented above as deletion with amplification. These results are higher than Harrison, 2009 [15] who reported amplification with a frequency of 5.8\%.

A high significant negative association between outcome and positive philidelphia chromosome, among the $11 \mathrm{ph}^{1}$ positive patients; nine patients had IR and only two patients had CR. these results are in agreement with Aldoss et al. [16].

However when the patients were divided according to $t(9 ; 22)$ in relation to different prognostic factors. It showed that most of $\mathrm{ph}^{1}$ positive ALL patients were presented with age $>35$ years and a high significant relation $(p=0.005)$ was detected between the patients age and $\mathrm{ph}^{1}$ positive ALL. As regards clinical findings in this work, all of $\mathrm{ph}^{1}$ positive ALL patients had hepatosplenomegaly with high significant relation $(\mathrm{p}=0.000)$ between them. While $9.1 \% \mathrm{of} \mathrm{ph}^{1}$ posi- 
tive ALL patients had lymphadenopathy with high significant, negative relation $(\mathrm{p}=0.000)$ between lymphadenopathy and $\mathrm{ph}^{1}$ ALL. The CNS infilteration in 9.1\% showed no significant association $(\mathrm{p}=0.482)$ to $\mathrm{ph}^{1}$, but these results differ from Ilana de Franc et al. [12] who stated no statistically significant differences between $\mathrm{BCR}-\mathrm{ABL}$ positive and negative patients in respect to the clinical variables.

As regards the hematological findings, there was high significant statistical association between $\mathrm{t}(9 ; 22)$ and TLC $\geq 50 \times 10^{9} / \mathrm{L}$ where $72.7 \%$ of $\mathrm{ph}^{1}$ positive ALL patients had TLC $\geq 50 \times 10^{9} / \mathrm{L}$ with $\mathrm{p}=0.001$ and with absolute PB blasts $\geq$ $4.4 \times 10^{9} / \mathrm{L}$ with $\mathrm{p}=0.001$. These findings are concordant with the previously published reports by Cetin et al. [17].

No significant statistical association was detected between $\mathrm{t}(9 ; 22)$ and $\mathrm{Hb}$ lev$\mathrm{el}<10 \mathrm{~g} / \mathrm{dl}(\mathrm{p}=0.123)$ and platelets $<100 \times 10^{9} / \mathrm{L}(\mathrm{p}=0.095)$. These finding are concordant with the previously published reports by Cetin et al. [17].

All the $\mathrm{ph}^{1}$ positive ALL patients in this work showed CD10 +ve (11 patients) with aberrant expression of $\mathrm{CD} 13$ or 33 in 5 patients, with no significant $(\mathrm{P}=$ $0.314)$ statistical association between $\mathrm{CD} 10$ and $\mathrm{t}(9 ; 22)$. Similary Sanam et al. [18] reported that CD10 expression had no statistical relationship with $t(9 ; 22)$. On the other hand, there was high negative significant association $(\mathrm{p}=0.000)$ between $\mathrm{t}(9 ; 22)$ and $\mathrm{CD} 13$ or 33 positive aberrant expression.

As regard the 8 patients with $\mathrm{ph}^{1}$ associated with other aberrations, there was significant statistical association between other aberrations (deletions, amplifications and duplication) and patients age $\geq 35$ years $(\mathrm{p}=0.046)$ and also with absolute-PB blasts $\geq 4.4 \times 10^{9} / \mathrm{L}$ with $(\mathrm{p}=0.001)$ while no significant statistical association could be detected with any of the following; gender, hepatomegaly, splenomegaly, lymphadenopathy, CNS infilteration, TLC $\geq 50 \times 10^{9} / \mathrm{L}$, Hb level $<10 \mathrm{~g} / \mathrm{dl}$, platelets $<100 \times 10^{9} / \mathrm{L}$ and IPT of CD10 \& CD13 or 33. According to our best knowledge, no previous studies had analyzed statistical relation between $\mathrm{BCR} / \mathrm{ABL}$ gene deletion, amplification or duplication and standard prognostic factors.

\section{Conclusion}

$\mathrm{BCR} / \mathrm{ABL}$ fusion gene analysis by ES-FISH may serve as a powerful prognostic marker in adulthood ALL. The age, TLC and $t(9 ; 22)$ represent the significant standard prognostic factors in relation to patient's outcome. Moreover, philidelphia chromosome with additional chromosomal abnormalities and gene amplification affecting BCR/ABL are efficiently detected by ES-FISH and show significant association with patient's outcome that may be used as prognostic indicators for therapeutic response.

\section{Acknowledgements}

We are thankful to all workers in the Hematology Unit of Clinical Pathology Department, Ain Shams University Hospital. 


\section{Author Contributions}

Dina Adel Fouad and Hasnaa Abo_Elwafaput the research idea, design of the work and final revision.

Ahmed Allam and Shereen Philip Aziz Participated in planning of the study and analysis of results and participated in manuscript writing.

Nesma Mokhtar collected the samples and participated in manuscript writing.

Compliance with ethical standards, anonymity and confidentiality of the subjects was maintained.

\section{Conflicts of Interest}

The authors declare no conflicts of interest regarding the publication of this paper.

\section{References}

[1] Shilpa, P., Hagop, K. and Elias, J. (2016) Adult Acute Lymphoblastic Leukemia. Mayo Clinic Proceedings, 91, 1645-1666.

https://doi.org/10.1016/j.mayocp.2016.09.010

[2] Moorman, A.V., et al. (2014) A Novel Integrated Cytogenetic and Genomic Classification Refines Risk Stratification in Pediatric Acute Lymphoblastic Leukemia. Blood, 124, 1434-1444. https://doi.org/10.1182/blood-2014-03-562918

[3] Ghazavi, F., Tim, L., Nadine, V.R., Bruce, P., Frank, S., Yves, B., Pieter, V.V. and Barbara, D.M. (2015) Molecular Basis and Clinical Significance of Genetic Aberrations in B-Cell Precursor Acute Lymphoblastic Leukemia. Experimental Hematology, 43, 640-653. https://doi.org/10.1016/j.exphem.2015.05.015

[4] Bachanova, V. (2017) Philadelphia-Positive Acute Lymphoblastic Leukemia: Do We Still Need Allogeneic Transplantation? Argument "Pro". Clinical Lymphoma Myeloma and Leukemia, 17, S10-S15. https://doi.org/10.1016/j.clml.2017.03.296

[5] Gersen, S. and Keagle, M. (2013) The Principles of Clinical Cytogenetics. 3rd Edition, Springer Science Business Media, New York. 561.

https://doi.org/10.1007/978-1-4419-1688-4

[6] Hu, L., Ru, K., Zhang, L., Huang, Y., Zhu, X., Liu, H., Zetterberg, A., Cheng, T. and Miao, W. (2014) Fluorescence In Situ Hybridization (FISH) an Increasingly Demanded Tool for Biomarker Research and Personalized Medicine. Biomarker Research, 2, 3. https://doi.org/10.1186/2050-7771-2-3

[7] Albano, F., Anelli, L., Zagaria, A., Archidiacono, N., Liso, V., Specchia, G. and Rocchi, M. (2007) "Home-Brew" FISH Assay Shows Higher Efficiency Than BCR-ABL Dual Color, Dual Fusion Probe in Detecting Microdeletions and Complex Rearrangements Associated with $\mathrm{t}(9 ; 22)$ in Chronic Myeloid Leukemia. Cancer Genetics and Cytogenetics, 174, 121-126.

https://doi.org/10.1016/j.cancergencyto.2006.09.025

[8] Lee, H.J., Thompson, J.E., Wang, E.S., et al. (2011) Philadelphia Chromosome Positive Acute Lymphoblastic Leukemia, Current Treatment and Future Perspectives. Cancer, 117, 583-594. https://doi.org/10.1002/cncr.25690

[9] Noreen, S., Zafar, I., Aamer, A., Tashfeen, A., Tahir, N. and Sultan, A. (2012) Prognostically Significant Fusion Oncogenes in Pakistani Patients with Adult Acute Lymphoblastic Leukaemia and Their Association with Disease Biology and Out- 
come. Asian Pacific Journal of Cancer Prevention, 13, 3349-3355. https://doi.org/10.7314/APJCP.2012.13.7.3349

[10] Schafer Eric, S., Margolin, J., Poplack, D.G. and Rabin, K.R. (2015) Molecular Genetics of Acute Lymphoblastic Leukemia. Molecular Basis of Cancer, 26, 395-406.

[11] Al Ustwani, O., Guptab, N., Bakhribaha, H., Griffithsa, E., Wanga, E. and Wetzler, M. (2016) Clinical Updates in Adult Acute Lymphoblastic Leukemia. Critical Reviews in Oncology/Hematology, 99, 189-199. https://doi.org/10.1016/j.critrevonc.2015.12.007

[12] de France, I., Rui Milton, P., Audrey Violeta, M., Washington, B., Fárida, C. and Raul, A. (2014) Frequency of p190 and p210 BCR-ABL Rearrangements and Survival in Brazilian Adult Patients with Acute Lymphoblastic Leukemia. Fundac, ão de Hematologia e Hemoterapia de Pernambuco (HEMOPE), 36, 351-355.

[13] Swerdlow, S.H., Campo, E., Pileri, S.A., Harris, N.L., Stein, H., Siebert, R., Advani, R., Ghielmini, M., Salles, G.A., Zelenetz, A.D. and Jaffe, E.S. (2016) The 2016 Revision of the World Health Organization Classification of Lymphoid Neoplasms, Blood, 127, 2375-2390. https://doi.org/10.1182/blood-2016-01-643569

[14] Seol, C.A., Cho, Y.U., Jang, S., Park, C.J., Lee, J.H., Lee, J.H., Lee, K.H. and Seo, E.J. (2017) Prognostic Significance of Recurrent Additional Chromosomal Abnormalities in Adult Patients with Philadelphia Chromosome-Positive Acute Lymphoblastic Leukemia. Cancer Genetics, 216, 29-36.

https://doi.org/10.1016/j.cancergen.2017.06.001

[15] Harrison, C.J. (2009) Cytogenetics of Paediatric and Adolescent Acute Lymphoblastic Leukaemia. British Journal of Haematology, 144, 147-156. https://doi.org/10.1111/j.1365-2141.2008.07417.x

[16] Aldoss, I., Tracey, S., Vinod, P., Joycelynne, P. and Stephen, F. (2015) The Prognostic Significance of Additional Cytogenetic Abnormalities in Adults with Philadelphia Chromosome Positive Acute Lymphoblastic Leukemia Undergoing Allogeneic Stem Cell Transplant. Clinical Lymphoma Myeloma and Leukemia, 15, S174-S175. https://doi.org/10.1016/j.clml.2015.04.012

[17] Cetin, Z., Sezin, Y., Ihsan, K., Alphan, K., Aysen, T., Ozan, S., Gulsun, T., Guchan, A., Demircan, O., Volkan, H., Mehmet, A.Y., Levent, U., Guven, L. and Sibel, B. (2012) Aberrations of Chromosomes 9 and 22 in Acute Lymphoblastic Leukemia Cases Detected by ES-Fluorescence In Situ Hybridization. Genetic Testing and Molecular Biomarkers, 16, 318-323. https://doi.org/10.1089/gtmb.2011.0186

[18] Loghavi, S., Kutok, J.L. and Jorgensen, J.L. (2015) B-Acute Lymphoblastic Leukemia/Lymphoblastic Lymphoma. American Journal of Clinical Pathology, 144, 393-410. https://doi.org/10.1309/AJCPAN7BH5DNYWZB 